\title{
Depth variation of the Conrad discontinuity in the Qaidam Basin, northwestern China, and its crustal dynamic implications
}

\author{
Biao Yang ${ }^{1}$, YanBin Wang ${ }^{1}$, Li Zhao', LiMing Yang ${ }^{2}$, and ChengNing Sha ${ }^{2}$ \\ 'Department of Geophysics, School of Earth and Space Sciences, Peking University, Beijing 100871, China; \\ ${ }^{2}$ Earthquake Administration of Qinghai Province, Xining 810001, China
}

Key Points:

- Broadband records from a dense seismic network were used to analyze the crustal phases and investigate the depth of the Conrad and Moho discontinuities in the Qaidam Basin.

- The depth of the Conrad discontinuity under the eastern part of the basin is shallower than the western part, which can be attributed to different crustal shortening mechanisms.

- The depth of the Moho discontinuity under the Qilian orogenic belt and Bayan Har block is deeper than under the Qaidam Basin, which is consistent with the previous results.

Citation: Yang, B., Wang, Y. B., Zhao, L., Yang, L. M. and Sha, C. N. (2021). Depth variation of the Conrad discontinuity in the Qaidam Basin, northwestern China, and its crustal dynamic implications. Earth Planet. Phys., 5(3), 296-304. http://doi.org/10.26464/epp2021030

\begin{abstract}
We use broadband records from a dense seismic network deployed in and around the Qaidam Basin in northwestern China to analyze the crustal phases and investigate the depth of the Conrad and Moho discontinuities as well as the P-wave velocity. Waveform cross-correlation is used to assist in the identification of the crustal phases and in determining their arrival times. Depth of the Conrad discontinuity is determined by fitting the travel times of Conrad-diffracted P-waves using a two-layer model. The depth of the Conrad discontinuity under the eastern part of the basin is shallower than the western part, which can be attributed to different crustal shortening mechanisms. The upper crust shortening in the western part of the basin leads to thickening of the upper crust, while multiple thrust faults result in the rise of the Conrad discontinuity in the east. These two different mechanisms determine the depth change of the Conrad discontinuity in the basin from the west to the east, which is supported by the results in this study.
\end{abstract}

Keywords: Conrad discontinuity; regional seismic data; crustal structure; Qaidam Basin; Tibetan Plateau

\section{Introduction}

The Qaidam Basin is located in the northern margin of the Tibetan Plateau (Figure 1) in northwestern China. It is surrounded by the Tarim block in the northwest, the Qilian block in the north and the Bayan Har block in the south. The Altyn Tagh Range in the northwest, the Qiman Tagh Thrust in the southwest, the North Kunlun Thrust in the south, and the Qilian Mountains in the north and east form the boundaries of the Qaidam Basin. The concentration of tectonic stress in the Tibetan Plateau results in strong tectonic activities in and around the basin (Huang $Y$ et al., 2017). The internal geological structure of the basin is very complex as a result of multiple cycles of sedimentation (Meng QR, 2009).

Many geophysical investigations have been conducted on the crustal structure of the Qaidam Basin. Teng JW et al. (1974) used deep crustal reflections recorded at distances of 40-90 km from deep seismic profiling in eastern Qaidam basin to infer the detailed crustal structure and confirmed the existence of the Conrad

Correspondence to: Y. B. Wang, ybwang@pku.edu.cn

Received 31 DEC 2020; Accepted 16 MAR 2021.

Accepted article online 14 APR 2021.

C) 2021 by Earth and Planetary Physics. discontinuity at a depth of $\sim 30$ kilometers. Teng JW et al. (1995) revealed from Rayleigh-wave dispersion that the crustal thickness of the Qaidam Basin is 42-58 kilometers. The velocity and Poisson ratio obtained by wide-angle seismic reflection/refraction data show that there is an obvious low-speed layer in the depth range of 12-20 kilometers in the north and south margins of the Qaidam Basin (Zhao JM et al., 2006).

Structural complexity in the mid-crust as a global phenomenon has been recognized since the very beginning of seismology. Conrad (1925) observed an arrival he named $\mathrm{P}^{*}$ when he examined records from an earthquake in Tauern, Austria. He interpreted $P^{*}$ arrival as a wave propagating immediately under a mid-crustal interface, analogous to Pn. Jeffreys (1926) subsequently determined the $P^{*}$ velocity as $6.5 \mathrm{~km} / \mathrm{s}$. Litak and Brown (1989) interpreted the discontinuity as the boundary between a granitic upper crust and a basaltic lower crust and the arrival traveling in the upper crustal layer was named Pg (for granitic). On seismic records, the discontinuity is manifested as a prominent $\mathrm{P}$-wave velocity $\left(V_{p}\right)$ that jumps from $6.1 \mathrm{~km} / \mathrm{s}$ to $6.7 \mathrm{~km} / \mathrm{s}$ (Merriam, 2006). The Conrad discontinuity has been identified on most continents (Nelson et al., 1985; Merriam, 2006), but is absent in oceanic crust and in continental crust with strong tectonic activity because it is 


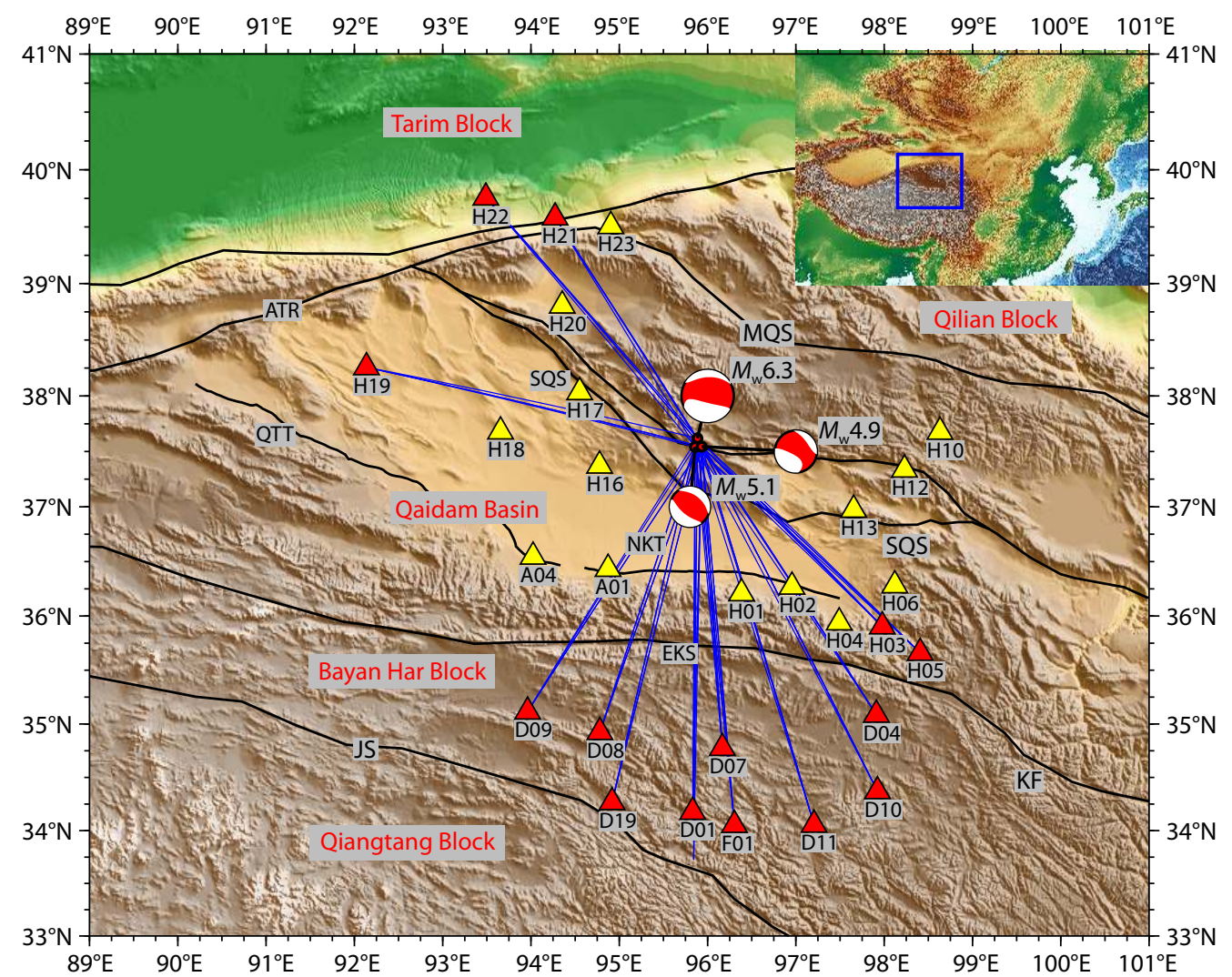

Figure 1. Tectonic setting and distributions of earthquakes and stations in the Qaidam Basin region. The yellow triangle represents the station used to constrain the velocity of the crust, while red triangles represent the stations used to constrain the velocity of the upper mantle and the depth of the Moho discontinuity. JS, EKS, SQS, MQS represent Jinshajiang Suture, East Kunlun Suture, South Qilian Suture and Middle Qilian Suture, respectively. KF, NKT, QTT and ATR represent Kunlun Fault, North Kunlun Thrust, Qiman Tagh Thrust and Altyn Tagh Range, repectively. Tectonic blocks and sutures refer to Zhang GM et al. (2005).

closely related to the evolution of the crust (Litak and Brown, 1989; Kerr, 1989).

The Kola Superdeep Borehole drilling program of the former Soviet Union (Clarke et al., 1986) did not provide supportive evidence for the existence of the lithologic discontinuity. Zhamaletdinov (2014) interpreted the Conrad discontinuity as a brittle-ductile transition at mid-crustal depth, based on the results from the deepest borehole Kola SG-3 (12262-meters depth) and seismic sounding.

Density profiles in the crust have also been used to infer the existence of mid-crustal discontinuity. Zhang YQ et al. (2017) obtained the density distribution in the eastern margin of the Tibetan Plateau by gravity inversion. The density changes abruptly at a depth of $\sim 28$ kilometers, which may be considered as the Conrad discontinuity. Earthquakes in the study area of Zhang YQ et al. (2017) are all distributed above the discontinuity, providing plausible evidence for the Conrad discontinuity as a brittle-ductile transition.

Ray tracing has been the most common method for studying the Conrad discontinuity. Figure 2 shows the basic phases in a twolayered crust model. He XB and Hong TK (2010) observed well-developed Conrad-refracted phases $\mathrm{P}^{*}$ and $\mathrm{S}^{*}$. Using the travel times of direct and reflected phases from 75 shallow crustal earthquakes, Bora and Baruah (2012) estimated that the depth of the

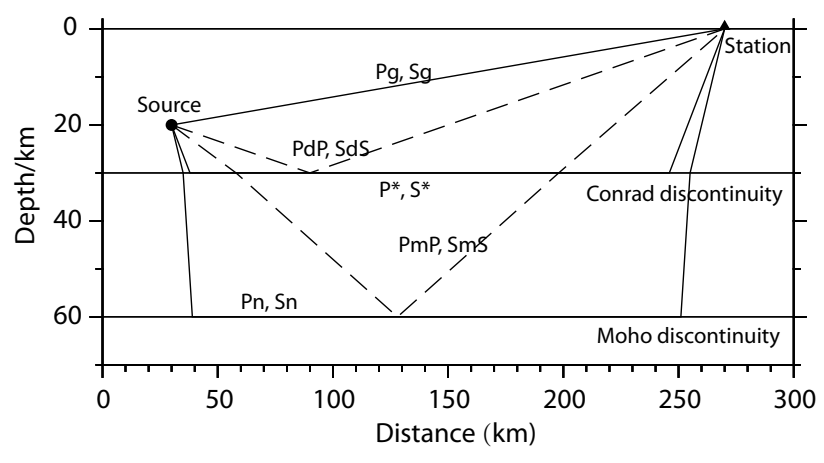

Figure 2. A schematic illustration of the ray paths of crustal phases in a two-layer crustal model. They include reflected phases PdP and SdS and refracted phases $P^{*}$ and $S^{*}$ from the Conrad discontinuity, reflected phases PmP and SmS, and refracted phases Pn and Sn from the Moho discontinuity, and the direct arrivals $\mathrm{Pg}$ and $\mathrm{Sg}$.

Conrad discontinuity in the Xilong Plateau, northeast India is 18 kilometers. Jiao YY et al. (2017) inferred the existence of the Conrad discontinuity in the northeast margin of the Tibet Plateau. Based on data from dense seismic arrays, Horiuchi et al. (1982), Oda and Ushio (2007), and Abdelwahed et al. (2013) obtained the lateral variations in the depths of the Conrad discontinuity in northeastern Japan, in Kyushu region and in Egypt. 
Studies on different sections of the Qaidam Basin all have found a discontinuity where the P-wave velocity jumps from $\sim 5.8 \mathrm{~km} / \mathrm{s}$ to $\sim 6.6 \mathrm{~km} / \mathrm{s}$ at a depth of $\sim 30 \mathrm{~km}$ (Teng JW, 1974; Cui ZZ et al., 1995; Xia WC et al., 2001; Wang YX et al., 2005; Guo B et al., 2019). In addition, a similar discontinuity was found in the Bayan Har and Qiangtang blocks in the south Qaidam Basin, at a depth of $\sim 30 \mathrm{~km}$ (Zhang ZJ and Klemperer, 2005; Jiang M et al., 2006).

Seismic observations in the Tibetan Plateau and surrounding regions (Ding ZF et al., 1999; Zou CQ et al., 2012; Zhang GM et al., 2019) have shown that travel-time residuals with respect to predictions by a two-layered average crustal model cannot be explained by the anisotropy in the crust when the epicentral distance is less than 300 kilometers. In this study, we use seismic waveforms recorded in the Qaidam Basin to investigate the lateral variations of the Conrad discontinuity by fitting the travel-times of crustal phases obtained from three regional crustal earthquakes. Further, we infer the average crustal structure of the Qaidam Basin.

\section{Data Analyses}

On November 10, 2008, an earthquake of magnitude $M_{\mathrm{w}} 6.3$ occurred in the northern margin of the Qaidam Basin (Figure 1). This earthquake, together with two moderate aftershocks, was recorded by the broadband seismic network deployed by the INDEPTH IV project since 2007 (Zhao WJ et al., 2008). We use the broadband waveform records of these earthquakes in this study. Table 1 provides information for the three earthquakes with focal mechanism solutions from the Global Centroid Moment Tensor (GCMT) catalog.

In order to identify the $\mathrm{Pg}, \mathrm{P}^{*}$, and $\mathrm{Pn}$ phases from the observed seismograms, we first calculate theoretical seismograms from the average crustal model of the Qaidam basin for the main shock and two aftershocks. According to the results of previous studies (Cui ZZ et al., 1995; Xia WC et al., 2001; Wang YX et al., 2005), the average $P$-wave velocity in the study region is about $6.6 \mathrm{~km} / \mathrm{s}$ at $30 \mathrm{~km}$, the average Moho depth is about $50 \mathrm{~km}$, and the wave velocity of the upper mantle is $8.0 \mathrm{~km} / \mathrm{s}$. There are sedimentary layers in the upper crust, and their average P-wave velocity is $5.43 \mathrm{~km} / \mathrm{s}$ (Zhang GM et al., 2019; Guo B et al., 2019). The S-wave velocity, density, and quality factor used in the modeling are referred to the AK135 model.

We computed theoretical seismograms with the focal mechanism (Table 1) provided by GCMT using the reflectivity method (Fuchs and Müller, 1971), and the travel-time curves of the crustal phases by the TauP Toolkit (Crotwell et al., 1999), as shown in Figure 3. With the help of the travel-time curves, the Conrad and Moho phases can be better distinguished. Figure 3 shows that in the range of 100-240 km, the refracted waves from the Conrad discontinuity are the first arrived seismic waves. When the epicentral distance is larger than $240 \mathrm{~km}$, the refracted waves from the Moho discontinuity are the first arrived seismic waves. The depth of the Moho discontinuity under the surrounding area of Qaidam basin can be inferred by the Pn phases.

After confirming the seismic phases of the simulated waveforms, we conducted cross-correlations of seismic waveforms between the main shock and the aftershocks to obtain the arrival times of $\mathrm{Pg}$ for the three events. By comparing with the simulated waveforms, the arrivals of the Pg were confirmed (Figure 4). Based on

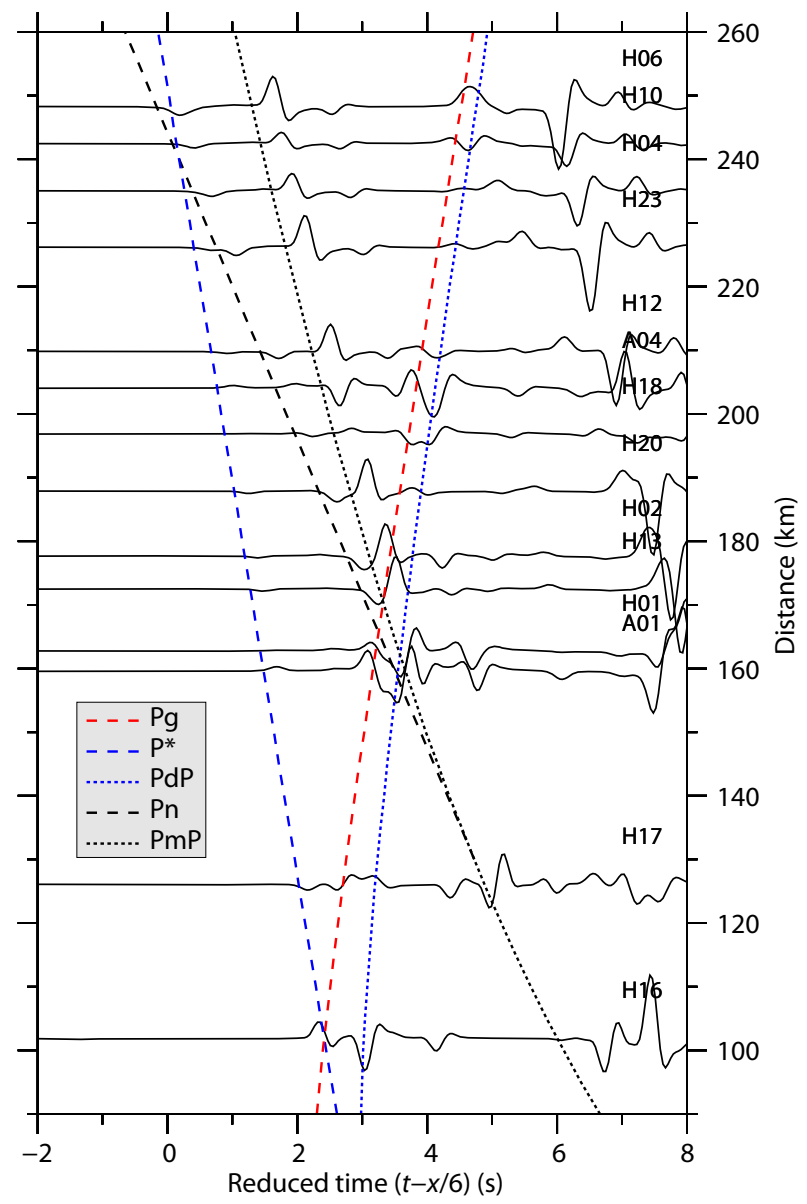

Figure 3. The theoretical seismograms simulated with the focal mechanism provided by GCMT by the reflectivity method (Fuchs and Müller, 1971) and the travel-time curves of the crustal phases by the TauP Toolkit for the main shock. With the help of the travel-time curve, the seismic phases can be confirmed.

Table 1. Information of earthquakes used in this study.

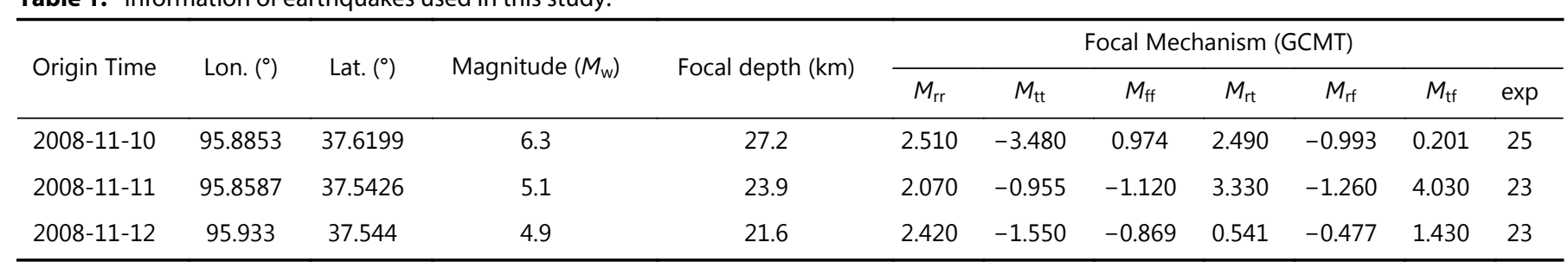



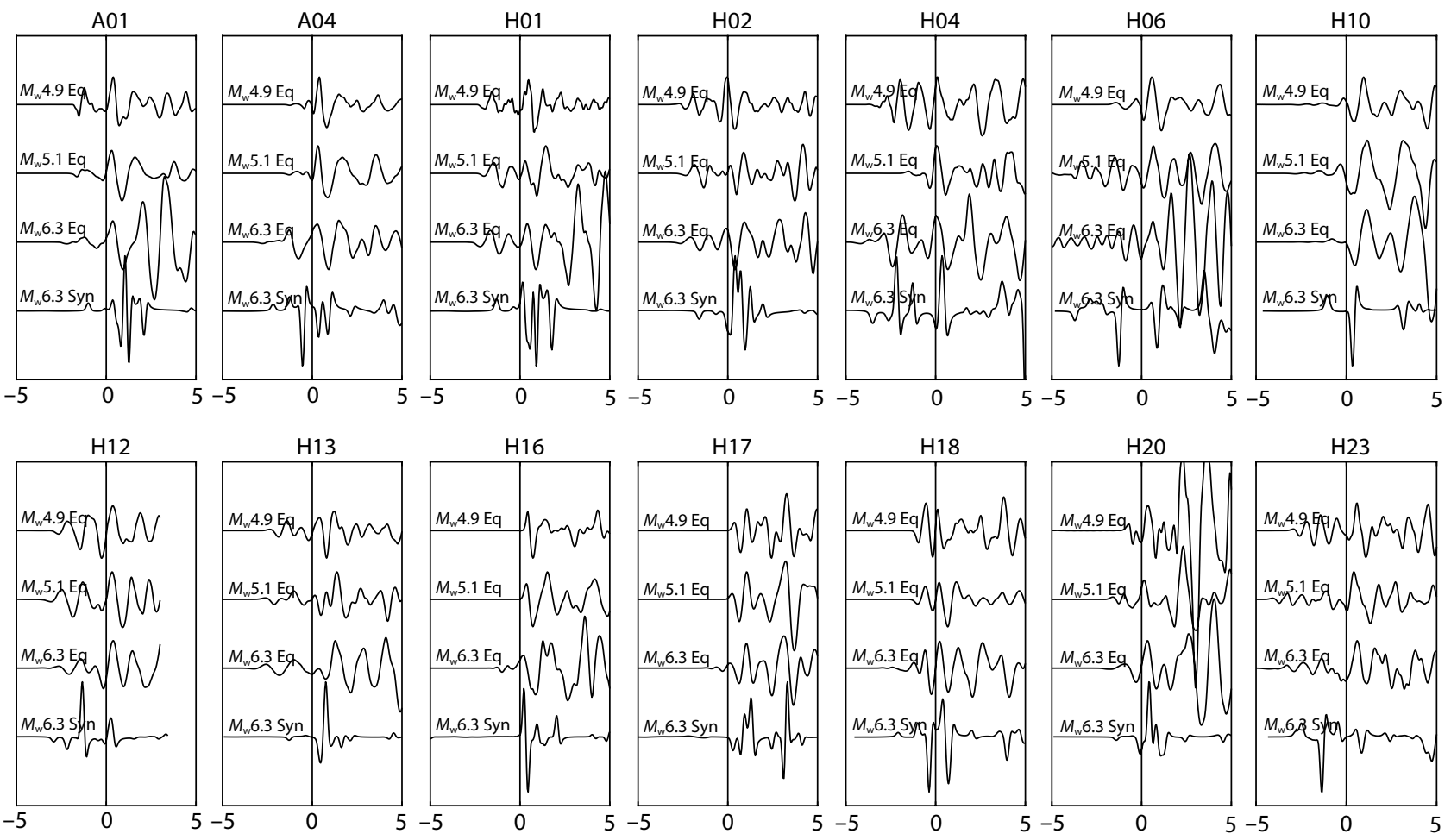

Figure 4. Observed waveforms of the vertical component from the main shock, the $M_{\mathrm{w}} 5.1$ and the $M_{\mathrm{w}} 4.9$ aftershocks at each station aligned by the Pg arrival times obtained by the cross-correlation with the synthetic waveforms. The vertical lines are the synthetic Pg arrival times. At each station, the cross-correlation is calculated in a 10-second time window from 5 seconds before and after the predicted arrival times of Pg. All waveforms are band-pass filtered with cutoff frequencies of $0.02 \mathrm{~Hz}$ and $1 \mathrm{~Hz}$. Each trace is self-normalized by its own maximum amplitude in the time window.

the arrival times of $\mathrm{Pg}$, we relocated the epicentral locations of the three earthquakes in order to minimize the error of epicentral distance estimation.

The $\mathrm{Pg}$ arrival times are picked from observed waveforms by reference to the synthetic $\mathrm{Pg}$ phases identified on the travel-time curve. As shown in Figure 4, the significant difference between the observed and synthetic waveforms of station A04 and $\mathrm{H} 06$ can be attributed for the impact of basin. For A04 and H06, the epicentral distances are 200 kilometers and 250 kilometers, respectively. If the picking time error is 2 seconds, then the errors of velocity of $\mathrm{Pg}$ are $0.03 \mathrm{~km} / \mathrm{s}$ and $0.015 \mathrm{~km} / \mathrm{s}$, resulting in errors of the estimated depth of the Conrad discontinuity and the depth of the Moho discontinuity smaller than $0.1 \%$, which are acceptable.

The arrival times of $\mathrm{Pg}$ and $\mathrm{P}^{*}$ can be expressed as Equation (1), Equation (2) and Equation (3), respectively.

$$
\begin{gathered}
t_{\mathrm{P}}=\frac{\sqrt{D^{2}+d^{2}}}{V_{\mathrm{pu}}} \approx \frac{D}{V_{\mathrm{pu}}}\left(1+\frac{1}{2}\left(\frac{d}{D}\right)^{2}\right), \\
t_{\mathrm{P} *}=\frac{\left(2 H_{\mathrm{c}}-d\right)}{\cos \theta_{\mathrm{c}}}\left(\frac{1}{V_{\mathrm{pu}}}-\frac{\sin \theta_{\mathrm{c}}}{V_{\mathrm{pl}}}\right)+\frac{D}{V_{\mathrm{pl}}} \\
t_{\mathrm{Pn}}=\frac{\left(2 H_{\mathrm{c}}-\mathrm{d}\right)}{\cos \theta_{\mathrm{c}}}\left(\frac{1}{V_{\mathrm{pu}}}-\frac{\sin \theta_{\mathrm{c}}}{V_{\mathrm{pl}}}\right)+\frac{\left(2 H_{\mathrm{m}}-2 H_{\mathrm{c}}\right)}{\cos \theta_{\mathrm{m}}}\left(\frac{1}{V_{\mathrm{pl}}}-\frac{\sin \theta_{\mathrm{m}}}{V_{\mathrm{pn}}}\right)+\frac{D}{V_{\mathrm{pn}}}
\end{gathered}
$$

$t_{\mathrm{P},}, t_{\mathrm{P}^{*},} t_{\mathrm{Pn}}$ are travel times of $\mathrm{Pg}, \mathrm{P}^{*}$ and $\mathrm{Pn}$, respectively. $V_{\mathrm{pu}}, V_{\mathrm{pl}}$ and $V_{\mathrm{pn}}$ are velocities of $\mathrm{P}$ wave in the upper crust, lower crust and upper mantle, respectively. $D$ is the epicentral distance and $d$ is the depth of earthquake. $H_{\mathrm{c}}$ is the depth of the Conrad discontinuity and $H_{\mathrm{m}}$ is the depth of the Moho discontinuity. $\theta_{\mathrm{c}}$ and $\theta_{\mathrm{m}}$ are the incident angles in the upper crust and lower crust.

The low velocity layer of upper crust (Teng JW, 1974; Cui ZZ et al., 1995; Xia WC et al., 2001; Wang ZJ et al., 2005) affects the critical incident angle $\theta_{c}$ of discontinuity and indirectly affects the estimation of interface depth. In the calculation of $\theta_{c}$ in equation $\sin \theta_{\mathrm{c}}=\frac{V_{\mathrm{pg}}}{V_{\mathrm{pl}}}$, we considered the low velocity layer by setting the velocity of $\mathrm{Pg}\left(V_{\mathrm{pg}}\right)$ to be $5.8 \mathrm{~km} / \mathrm{s}$ that is the $\mathrm{P}$ wave velocity of the low velocity layer.

Equations (1)-(3) are all based on a 1-D velocity model, representing the average depth of a profile for a station-epicenter pair with a certain azimuth, which could reflect spatial variation of the discontinuities around Qaidam Basin.

\section{Results}

\subsection{Average Two-layer Crustal Model}

We first picked the arrival times of $\mathrm{Pg}, \mathrm{P}^{*}$ and $\mathrm{Pn}$ from waveforms of the main shock and two aftershocks, and then fitted the arrival times with the least-squares criterion to obtain the average velocities of the upper crust, the lower crust and the upper mantle. We then estimated the depth of the Conrad and the Moho discontinuities using the average velocities and Equations (1), (2), and (3). Before the regression of the arrival times, the error caused by 
the difference in focal depths of the three earthquakes are eliminated by Equations (1), (2), and (3).

Figure 5 shows the variations of the measured travel times of $\mathrm{Pg}$, $\mathrm{P}^{*}$ and $\mathrm{Pn}$ from the three earthquakes with epicentral distance. The travel times fit well with good linear relationships and small standard deviations, consistent with the arrival times expressed by the equations. The standard deviation of fitting the arrival times of $\mathrm{Pg}$ comes from the inhomogeneity of P-wave velocity in crust and the error of epicentral distance. After relocation, the maximum shifts of epicenters are 2.1, 6.4 and 7 kilometers and arrival time errors due to the mislocation are 0.3 second, 0.9 second and 1.1 second, respectively. The epicentral distance $D$ was affected by mislocation, attributing to 0.4092 kilometers, 1.2471 kilometers, and 1.364 kilometers of error for the depth of the Conrad discontinuity $\left(H_{\mathrm{c}}\right)$ and smaller errors for the depth of the Moho discontinuity $\left(H_{m}\right)$. Hence the variance mainly reflects the errors from the heterogeneity in the upper crust and mantle. The standard deviation of fitting the arrival times of $\mathrm{P}^{*}$ and $\mathrm{Pn}$ comes from the inhomogeneity of P-wave velocity in crust and the variation of depth of discontinuity. The standard deviation of fitting the arrival times of $P^{*}$, which is larger than that of $\mathrm{Pg}$ and $\mathrm{Pn}$, indicates that there is a significant depth variation of the Conrad discontinuity under the Qaidam Basin

\subsection{Variation of the Depth of the Conrad Discontinuity}

As shown in Figure 5, there are discrepancies in the arrival times of $\mathrm{Pg}, \mathrm{P}^{*}$ and $\mathrm{Pn}$ at some stations between predictions from the two-layer crust model and the observations. P-wave tomography of the Tibetan Plateau shows that P-wave velocity variations in Qaidam Basin are within $\pm 0.2 \mathrm{~km} / \mathrm{s}$ and $\pm 0.1 \mathrm{~km} / \mathrm{s}$ around the depths of $10 \mathrm{~km}$ and $30 \mathrm{~km}$, respectively (Ding ZF et al., 1999). Teleseismic P-wave tomography for the Qiangtang block revealed that lateral heterogeneities of P-wave velocity around 20-km depth are within 2\% (Zou CQ et al., 2012). Besides, a recent $\mathrm{P}$-wave tomography indicated that the P-wave variations in the Qaidam Basin around 10-km depth are within 2\% (Zhang GM et al., 2019). According to the fitting results of $\mathrm{Pg}$ and $\mathrm{Pn}$, the standard deviation attributed to the heterogeneities of $\mathrm{P}$-wave velocity is up to 0.64 . However, for the $P^{*}$ phase, the standard deviation of fitting the arrival times is larger than 0.94 , which indicates a considerable depth variation of the Conrad discontinuity under the Qaidam Basin.

Using the measured arrival times of $\mathrm{P}^{*}$ phase at different stations (Figure 5) and the average two-layer crustal model, we can estimate the average depth of the Conrad discontinuity at each station. The histograms in Figure 6 show the depth variations of the Conrad discontinuity obtained from the three earthquakes. It can be seen that the depths of discontinuity obtained by the three earthquakes are relatively consistent.

The large deviation of the depth of the Conrad discontinuity at some stations such as $\mathrm{H} 06, \mathrm{H} 18$ estimated from three earthquakes indicates that the error of epicentral distance still affects the estimation of the depth of discontinuity. After relocation, the error of epicentral distance is within \pm 5 kilometers. The arrival time error is calculated by considering the error of epicentral distance and the velocity of $\mathrm{Pg}$. Thus, the maximum arrival time error due to the impact of epicentral distance error is 0.51 second.

Figure 6 shows the variations and error range of the average depth of the Conrad discontinuity obtained from the results of the three earthquakes. According to previous results, P-wave velocity variations in Qaidam Basin are $\pm 0.1 \mathrm{~km} / \mathrm{s}$ at the depth of $30 \mathrm{~km}$ (Ding ZF et al., 1999). The left and right bounds of P-wave velocity at each station in the lower crust are set as $6.46 \mathrm{~km} / \mathrm{s}$ and $6.66 \mathrm{~km} / \mathrm{s}$. The gray scale represents the average travel time error of three earthquakes. Because the largest impact of epicentral distance on travel-time is 0.51 seconds, the depths associated with travel-time error which is less than 0.51 seconds are considered as the range of the Conrad discontinuity.

It can be seen that from the east to the west, and from the south to the north, that the depth of the Conrad discontinuity gradually deepens. In the study of Yin A et al. (2007), the depth of the main Qaidam detachment fault similarly gradually deepens from east to west and from south to north. The former is attributed to different crustal thickening patterns, while the latter is the result of re-
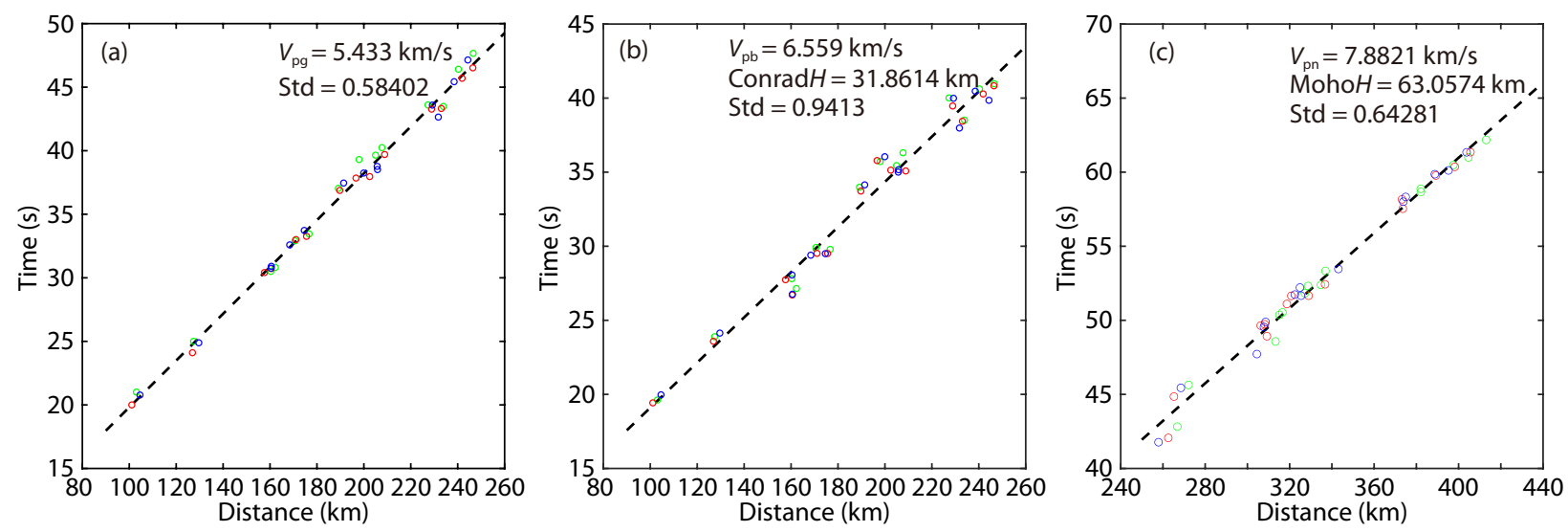

Figure 5. (a) Variation of the Pg travel times with epicentral distance obtained from the $M_{\mathrm{w}} 6.3$ main shock (green circles), $M_{\mathrm{w}} 5.1$ aftershock (red circles) and $M_{\mathrm{w}} 4.9$ aftershock (blue circles). Circles are measurements at individual stations, while the dashed line is their linear fit. (b) Same as (a) but for $\mathrm{P}^{*}$. (c) Same as (a) but for Pn. The resulting depths of the Conrad and the Moho discontinuities are 31.86 kilometers and 63.05 kilometers, respectively, and the $P$-wave velocities in the lower crust and upper mantle are $6.56 \mathrm{~km} / \mathrm{s}$ and $7.88 \mathrm{~km} / \mathrm{s}$, respectively. 


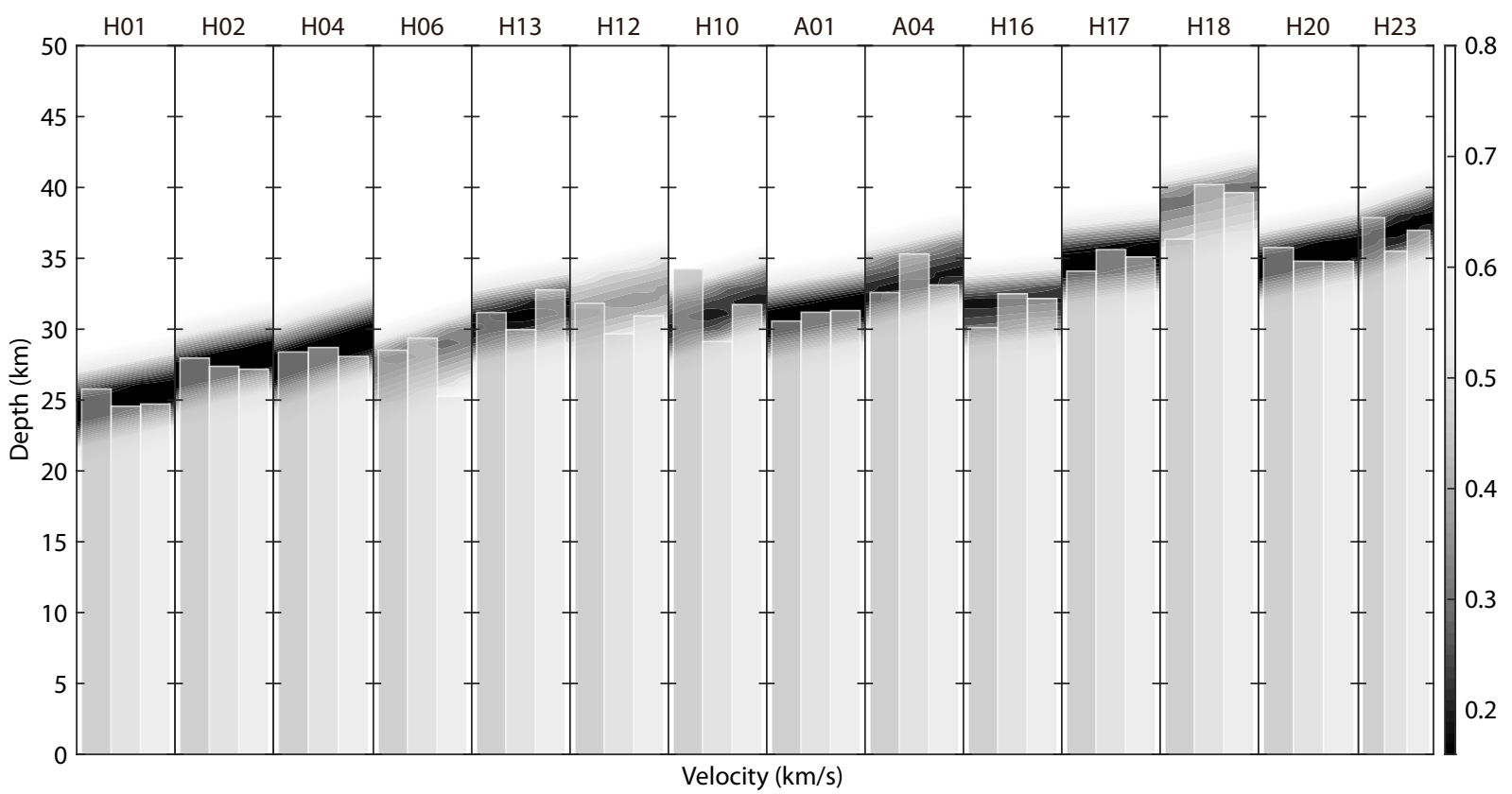

Figure 6. From left to right, histograms represent estimated depths of the Conrad discontinuity at individual stations obtained from the $M_{\mathrm{w}} 6.3$ mainshock and the $M_{\mathrm{w}} 5.1$ and $M_{\mathrm{w}} 4.9$ aftershocks, respectively. The left and right bounds of P-wave velocity at each station in the lower crust are set as $6.46 \mathrm{~km} / \mathrm{s}$ and $6.66 \mathrm{~km} / \mathrm{s}$. The gray scale represents the average travel time error of three earthquakes. $\mathrm{H01}, \mathrm{H} 02, \mathrm{H} 04, \mathrm{H} 06, \mathrm{H} 13, \mathrm{H} 12$, and $\mathrm{H} 10$ stations are located in the eastern basin from south to the north, while $\mathrm{A01}, \mathrm{A04}, \mathrm{H} 16, \mathrm{H} 17, \mathrm{H} 18$ stations are located in the western basin from south to the north.

peated thrusting in the lower crust. The depth of the Conrad discontinuity in the central western basin $(\mathrm{H} 18)$ is significantly larger than other parts of the basin, indicating a more severe crustal deformation and concave upper crust in the western basin. Previous results (Teng JW, 1974; Yue H et al., 2012) show that the thickness of crust of western Qaidam Basin is 54 kilometers, which is much larger than that of eastern Qaidam Basin, which is 45 kilometers. The variation of the Moho discontinuity under the basin is coherent with the variation of the Conrad discontinuity due to the crust shortening.

Figure 7 shows the depth variations of the Moho discontinuity obtained from the three earthquakes and estimated average depths of the Moho discontinuity at individual stations. It can be seen that the depths of discontinuity obtained by the three earthquakes are relatively consistent. The depth obtained in this study is basically consistent with the depth obtained by Yue $\mathrm{H}$ et al. (2012). The depth of the Moho discontinuity in the northwest of Qaidam Basin obtained by Yue $\mathrm{H}$ et al. (2012) varies greatly (H21, $\mathrm{H} 22$ ), while the depth obtained in this study is deeper than the former, which indicates that there is a deep the Moho discontinuity under the Qilian Mountain. The profile obtained by Wang ZJ et al., (2005) shows that the Moho discontinuity under the Qilian block is concave, and the thickest crust is about $73 \mathrm{~km}$ which is consistent with our estimation.

The depth of the Moho discontinuity in the northwestern basin $(\mathrm{H} 19)$ is significantly larger than for other parts of the basin in agreement with the results of Zhang GM et al., (2019) indicating a more severe crustal deformation and thickened crust there.

It can also be seen that the depth of the Moho discontinuity in- creases dramatically once crossing the Kunlun Mountains. The depths of Moho at station $\mathrm{H03}, \mathrm{H} 05$ are obviously shallower than other stations. Previous studies indicate that there is a Moho offset at the easternmost Qaidam-Kunlun boundary (Vergne et al., 2002; Jiang M et al., 2006; Shi DN et al., 2009).

In general, the depth of the Moho discontinuity under the Qilian orogenic belt $(\mathrm{H} 21, \mathrm{H} 22)$ and Bayan Har block (D01, D04, D07, D08, D09, D10, D11, D19, F01) is deeper than under the Qaidam Basin (H03, H05, H19), which is consistent with previous results (Vergne et al., 2002; Wang ZJ et al., 2005; Jiang M et al., 2006; Shi DN et al., 2009; Yue $\mathrm{H}$ et al., 2012) and gravity isostasy.

\section{Discussion}

Previous studies on the evolution of the geothermal field in the Qaidam Basin have shown that the geothermal gradient in the basin has been rising continuously since the Holocene (Yu SL et al., 2006). Lithospheric geothermal data show that the temperature under the Qaidam Basin reaches $500^{\circ} \mathrm{C}$ at a depth of 30 kilometers (Zhao JM, 2012), suggesting a brittle to ductile transition in the mid crust.

Previous studies have shown that there exists a low-velocity layer at the $\sim 30 \mathrm{~km}$ depth where P-wave velocity jumps from $5.8 \mathrm{~km} / \mathrm{s}$ to $6.6 \mathrm{~km} / \mathrm{s}$ in the Qaidam Basin (Cui ZZ et al., 1995; Xia WC et al., 2001; Wang YX et al., 2005). A low-velocity layer was also found at $\sim 30 \mathrm{~km}$ depth in the crust of Qiangtang and Bayan Har blocks (Zhang ZJ and Klemperer, 2005; Jiang M et al., 2006). Summarizing previous results, a low velocity layer exists in the Tibetan Plateau with a mild lateral change (Teng JW et al., 2012). This was inferred as the evidence for the decoupling of the upper and lower 


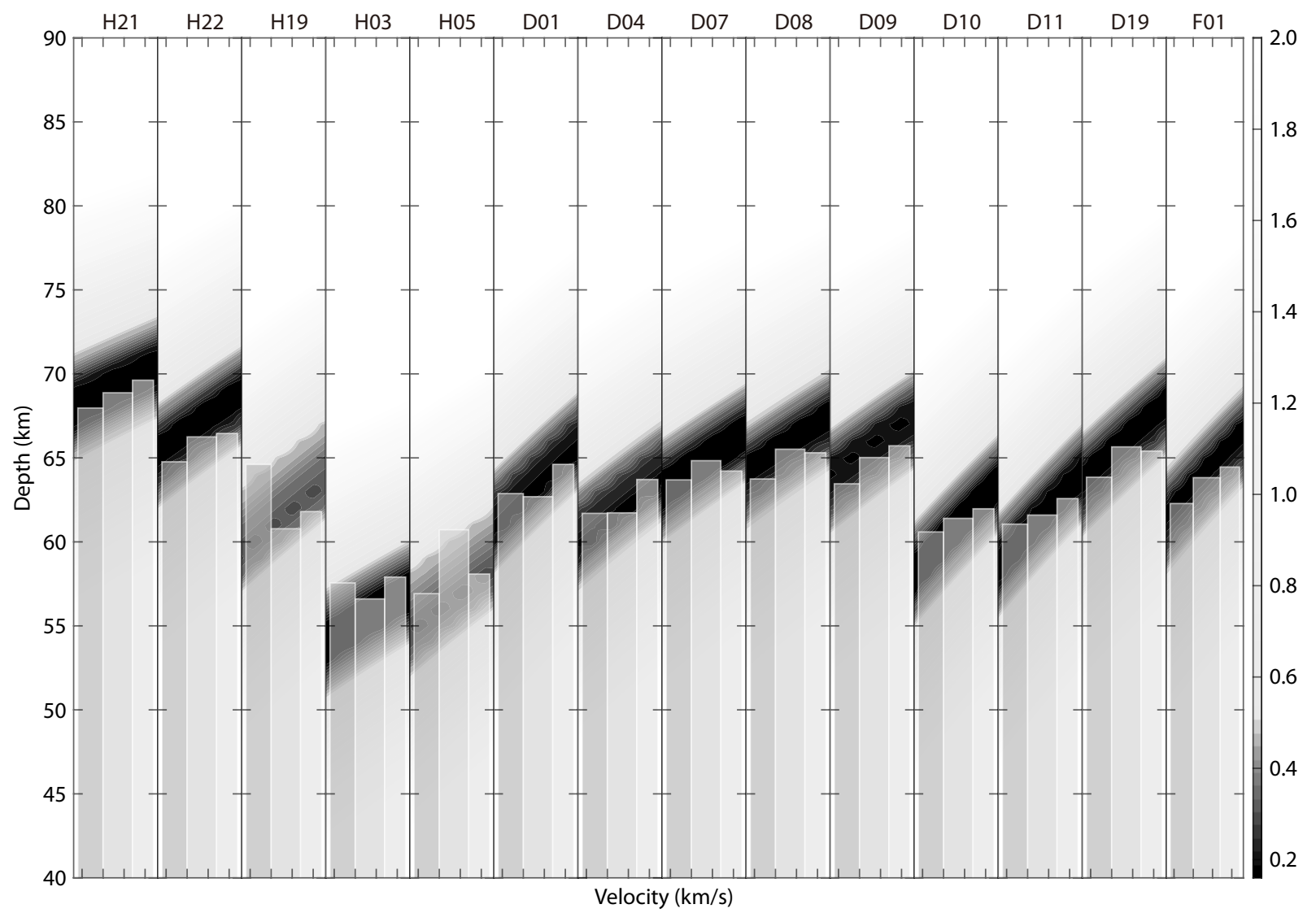

Figure 7. From left to right, histograms represent estimated depths of the Moho discontinuity at individual stations obtained from the $M_{\mathrm{w}} 6.3$ mainshock and the $M_{\mathrm{w}} 5.1$ and $M_{\mathrm{w}} 4.9$ aftershocks, respectively. The left and right bounds of P-wave velocity at each station in the upper mantle are set as $7.78 \mathrm{~km} / \mathrm{s}$ and $7.98 \mathrm{~km} / \mathrm{s}$. The gray scale represents the average travel-time error of the three earthquakes.

crust of the Tibet Plateau and constituted the upper sliding surface for the material flow in the deeper part of the plateau. The oblique continental subduction model predicts the decoupling of the crust and mantle lithosphere. Vertical strike-slip faults are rooted in subduction zones, enabling the continental lithosphere to move laterally (Wang CS et al., 2011).

Deep seismic reflection studies have shown that a group of multilayer detachment faults with a cumulative thickness of 6-9 km developed in the mid-crust, in a depth range of $30-40 \mathrm{~km}$ in the northern margin of the Tibetan Plateau (Wang CS et al., 2011). These detachment faults block the extension of the left-lateral strike-slip Kunlun Fault. The shortening of continental lithosphere in the northern margin of the Tibetan Plateau led to the stress concentration on the weak mid-crust, resulting in simple shear zones. The shear zones act as the buffer zones connecting the upper and lower crust. The depth and thickness of the detachment faults obtained in previous studies are consistent with a low-velocity layer in the upper crust, while the lower boundary of this layer may correspond to the Conrad discontinuity derived in this study.

Across the Qaidam Basin, the relative shortening of the upper crust decreases from more than $48 \%$ in the west to less than $1 \%$ in the east, which suggests a shift of crustal shortening from the upper crust to the lower crust (Yin A et al., 2007). Because the materials at the depths of lower crust and upper mantle under the
Qaidam Basin are relatively rigid, as indicated by relatively high velocity and $Q$ value (Teng JW et al., 2012), the crustal thickening in eastern Qaidam Basin is probably the result of repeated thrusting in the lower crust (Yin A et al., 2007).

The depth of the detachment fault under the Qaidam Basin gradually decreases from $\sim 28$ kilometers in the west to $\sim 16$ kilometers, in the east (Yin A et al., 2007). Referring to the 6-9 km thickness of the detachment fault zone obtained by Wang CS et al. (2011), the depth of the lower boundary of the detachment fault zone under the Qaidam Basin changes from 34-37 km in the west, to $22-27 \mathrm{~km}$ in the east, which is in good agreement with our results for the depth of the Conrad discontinuity. It is unlikely that faulting can occur below the depth of the Conrad discontinuity where the rock becomes ductile, so the detachment faults can only extend along the Conrad discontinuity. This is why the variation in the depth of the detachment fault zone has a similar pattern to the Conrad discontinuity obtained in this study.

\section{Conclusion}

The $M_{\mathrm{w}} 6.3$ earthquake occurred on November 10, 2008 and its aftershocks were recorded by the broadband seismic stations deployed by the INDEPTH IV Project. In this study, we have confirmed the existence of the Conrad discontinuity in the Qaidam Basin by analyzing these seismic data. 
The Conrad discontinuity has a depth of $\sim 35 \mathrm{~km}$ in the western part of the basin, greater than in the eastern part. The shortening of the upper crust in the west results in the deepening of the Conrad discontinuity, while in the east the crustal shortening is shifted to the lower crust, leading to the rise in the Conrad discontinuity. Our result for the variation in the depth of the Conrad discontinuity in the Qaidam Basin is consistent with the previously reported patterns in the depths of the detachment faults and lowvelocity layer in mid crust. The lower boundary of the detachment fault zone is the Conrad discontinuity and corresponds to the transition of the crustal rock property from brittle to ductile.

The deeper Conrad and Moho discontinuity in the northwest part of Qaidam Basin both indicate that the crust of this region had undergone more severe deformation and formed thicker upper crust.

\section{Acknowledgments}

The authors acknowledge the fieldwork of the International Deep Profiling of Tibet and the Himalaya Phase IV (IN- DEPTH IV) project team for data acquisition. This work was supported by the National Natural Science Foundation of China (Grant Number 41930103, 41674052). Figures are generated by the Generic Mapping Tools 5.4.3 (Wessel et al., 2019) and MATLAB. The authors acknowledge the course English Presentation for Geophysical Research of Peking University for help in improving this manuscript.

\section{References}

Abdelwahed, M. F., El-Khrepy, S., and Qaddah, A. (2013). Three-dimensional structure of Conrad and Moho discontinuities in Egypt. J. Afr. Earth Sci., 85, 87-102. https://doi.org/10.1016/j.jafrearsci.2013.04.007

Bora, D. K., and Baruah, S. (2012). Depth of mid-crustal discontinuity from reflected seismic waves on local earthquake seismograms recorded at Shillong Plateau, Northeast India. Geomat. Nat. Hazards Risk, 3(4), 355-364. https://doi.org/10.1080/19475705.2012.668564

Clarke, J. W., McDowell, R. C., Matzko, J. R., Hearn, P. P., Milton, D. J., Percious, D. J., Vitaliano, D. B., and Ulmishek, G. (1986). The Kola Superdeep drill Hole by Ye. A. Kozlovskiy (1984): A Detailed Summary. USGS Open File Report, 86-517, 1986. https://doi.org/10.3133/ofr86517

Conrad, V. (1925). Laufzeitkurven des Tauernbebens vom 28. November, 1923. Mitt Erdb Komm Wien Akad Wiss, 59: 1-23

Crotwell, H. P., Owens, T. J., and Ritsema, J. (1999). The taup toolkit: flexible seismic travel-time and ray-path utilities. Seismol. Res. Lett., 70(2), 154-160. https://doi.org/10.1785/gssrl.70.2.154

Cui, Z. Z., Li, Q. S., Wu, C. D., Yin, Z. X., and Liu, H. B. (1995). The crustal and deep structures in Golmud-Ejin Qi Ggt. Acta Geophys. Sin. (in Chinese), 38(S2), 15-18.

Ding, Z. F., He, Z. Q., Sun, W. G., and Sun, H. C. (1999). 3-D crust and upper mantle velocity structure in eastern tibetan plateau and its surrounding areas. Chin. J. Geophys. (in Chinsese), 42(2), 197-205. https://doi.org/10.3321/j.issn:0001-5733.1999.02.007

Fuchs, K., and Müller, G. (1971). Computation of synthetic seismograms with the reflectivity method and comparison with observations. Geophys. J. Int., 23(4), 417-433. https://doi.org/10.1111/j.1365-246X.1971.tb01834.x

Guo, B., Chen, J. H., Liu, Q. Y., and Li, S. C. (2019). Crustal structure beneath the Qilian Orogen Zone from multiscale seismic tomography. Earth Planet. Phys., 3(3), 232-242. https://doi.org/10.26464/epp2019025

He, X. B., and Hong, T. K. (2010). Evidence for strong ground motion by waves refracted from the conrad discontinuity. Bull. Seismol. Soc. Am., 100(3), 1370-1374. https://doi.org/10.1785/0120090159

Horiuchi, S., Ishii, H., and Takagi, A. (1982). Two-dimensional depth structure of the crust beneath the Tohoku district, The Northeastern Japan Arc Part I. Method and conrad discontinuity. J. Phys. Earth, 30(1), 47-69.

https://doi.org/10.4294/jpe1952.30.47

Huang, Y., Chen, Y. Y., and Wang, Y. B. (2017). Amplification effect of seismic ground motion at the eastern part of Qaidam basin. China Earth. Eng. J. (in Chinese), 39(3), 534-544.

Jeffreys, H. (1926). On near earthquakes. Geophys. J. Int., 1(S8), 385-402. https://doi.org/10.1111/j.1365-246X.1926.tb05386.x

Jiang, M., Galvé, A., Hirn, A., de Voogd, B., Laigle, M., Su, H. P., Diaz, J., Lépine, J. C., and Wang, Y. X. (2006). Crustal thickening and variations in architecture from the Qaidam basin to the Qang Tang (North-Central Tibetan Plateau) from wide-angle reflection seismology. Tectonophysics, 412(3-4), 121-140. https://doi.org/10.1016/j.tecto.2005.09.011

Jiao, Y. Y., Shen, X. Z., and Li, Q. S. (2017). Seismic evidence of the conrad discontinuity on the northeast margin of the tibetan plateau and a tentative discussion on its tectonic implications. Acta Geosci. Sin. (in Chinese), 38(4), 469-478. https://doi.org/10.3975/cagsb.2017.04.04

Kerr, R. A. (1989). Deep holes yielding geoscience surprises. Science, 245(4917), 468-470. https://doi.org/10.1126/science.245.4917.468

Litak, R. K., and Brown, L. D. (1989). A modern perspective on the Conrad discontinuity. Eos Trans. Am. Geophys. Union, 70(29), 713-725. https://doi.org/10.1029/89EO00223

Meng, Q. R. (2009). Some remarks on formation of the Qaidam basin. Chin. J. Geol. (in Chinese), 44(4), 1213-1226. https://doi.org/10.3321/j.issn:05635020.2009.04.013

Merriam, D. F. (2006). The Conrad discontinuity in the midcontinent (USA). Trans. Kansas Acad. Sci., 109(3-4), 125-130.

Nelson, K. D., Arnow, J. A., McBride, J. H., Willemin, J. H., Huang, J., Zheng, L., Oliver, J. E., Brown, L. D., and Kaufman, S. (1985). New COCORP profiling in the southeastern United States. Part I: late paleozoic suture and Mesozoic rift basin. Geology, 13(10), 714-718. https://doi.org/10.1130/00917613(1985)13<714:NCPITS>2.0.CO;2

Oda, H., and Ushio, T. (2007). Topography of the moho and conrad discontinuities in the Kyushu district, Southwest Japan. J. Seismol., 11(2), 221-233. https://doi.org/10.1007/s10950-007-9049-z

Shi, D. N., Shen, Y., Zhao, W. J., and Li, A. B. (2009). Seismic evidence for a Moho offset and south-directed thrust at the easternmost Qaidam-Kunlun boundary in the Northeast Tibetan plateau. Earth Planet. Sci. Lett., 288(1-2), 329-334. https://doi.org/10.1016/j.epsl.2009.09.036

Teng, J. W. (1974). Deep reflected waves and the structure of the earth crust of the eastern part of Chaidam basin. Acta Geophys. Sin. (in Chinese), 17(2), 122-135.

Teng, J. W., Hu, J. F., Zhang, Z. J., Wang, A. W., Sun, X. L., Yang, Z. S., Yang, D. H., and Wan, Z. C. (1995). The 3-D structure of rayleigh wave and sedimentary basins in Northwest China. Acta Geophys. Sin. (in Chinese), 38(6), 737-749.

Teng, J. W., Yuan, X. M., Zhang, Y. Q., Hu, G. Z., and Yan, Y. F. (2012). The stratificational velocity structure of crust and covering strata of upper mantle and the orbit of deep interaquifer substance locus of movement for Tibetan Plateau. Acta Petrol. Sin. (in Chinese), 28(12), 4077-4100.

Vergne, J., Wittlinger, G., Hui, Q., Tapponnier, P., Poupinet, G., Mei, J., Herquel, G., and Paul, A. (2002). Seismic evidence for stepwise thickening of the crust across the NE Tibetan plateau. Earth Planet. Sci. Lett., 203(1), 25-33. https://doi.org/10.1016/S0012-821X(02)00853-1

Wang, C. S., Gao, R., Yin, A., Wang, H. Y., Zhang, Y. X., Guo, T. L., Li, Q. S., and Li, Y. L. (2011). A mid-crustal strain-transfer model for continental deformation: a new perspective from high-resolution deep seismic-reflection profiling across NE Tibet. Earth Planet. Sci. Lett., 306(3-4), 279-288. https://doi.org/10.1016/j.epsl.2011.04.010

Wang, Y. X., Mooney, W. D., Han, G. H., Yuan, X. C., and Jiang, M. (2005). Crustal P-wave velocity structure from Altyn Tagh to Longmen mountains along the Taiwan-Altay geoscience transect. Chin. J. Geophys. (in Chinese), 48(1), 98-106.

Wessel, P., Luis, J. F., Uieda, L., Scharroo, R., Wobbe, F., Smith, W. H. F., and Tian, D. (2019). The generic mapping tools version 6. Geochem. Geophy. Geosyst., 20(11), 5556-5564. https://doi.org/10.1029/2019GC008515

Xia, W. C., Zhang, N., Yuan, X. P., Fan, L. S., and Zhang, B. S. (2001). Cenozoic 
Qaidam basin, China: a stronger tectonic inversed, extensional rifted basin. AAPG Bulletin, 85(4), 715-736.

Yin, A., Dang, Y. Q., Chen X. H., Wang, L. Q., Jiang, W. M., Jiang, R. B., Wang, X. F., Zhou, S. P., Liu, M. D., and Ma, L. X. (2007). Cenozoic evolution and tectonic reconstruction of the Qaidam basin: evidence from seismic profiles. J. Geomech. (in Chinese), 13(3), 193-211. https://doi.org/10.3969/j.issn.10066616.2007.03.001

Yu, S. L., Ji, J. Q., Chen, J. J., and Zhang, X. Y. (2006). Lower crust flow and largescale geomorphy of Qinghai-Tibet Plateau. Geol. Sci. Technol. Inf. (in Chinese), 25(5), 1-7, 20. https://doi.org/10.3969/j.issn.1000-7849.2006.05.001

Yue, H., Chen, Y. J., Sandvol, E., Ni, J., Hearn, T., Zhou, S. Y., Feng, Y. G., Ge, Z. X., Trujillo, A., ... Liu, Z. (2012). Lithospheric and upper mantle structure of the northeastern Tibetan Plateau. J. Geophys. Res., 117(B5), B05307. https://doi.org/10.1029/2011JB008545

Zhamaletdinov, A. A. (2014). The nature of the conrad discontinuity with respect to the results of kola superdeep well drilling and the data of a deep geoelectrical survey. Dokl. Earth Sci., 455(1), 350-354. https://doi.org/10.1134/S1028334X14030325

Zhang G. M., Ma H. S., Wang H., Wang X. L. (2005). Boundaries between activetectonic blocks and strong earthquakes in the China mainland. Chinese J. Geophys. (in Chinese), 48(3), 602-610.

Zhang, G. M., Li, X. B., Zheng, C., and Song, X. D. (2019). Crustal and uppermost mantle velocity structure beneath the central-eastern Tibetan Plateau from P-wave tomography. Acta Seismol. Sin. (in Chinsese), 41(4), 411-424. https://doi.org/10.11939/jass.20190003

Zhang, Y. Q., Teng, J. W., Wang, Q. S., Lü, Q. T., Si, X., Xu, T., Badal, J., Yan, J. Y., and Hao, Z. B. (2017). A gravity study along a profile across the Sichuan Basin, the Qinling Mountains and the Ordos Basin (central China): density, isostasy and dynamics. J. Asian Earth Sci., 147, 310-321. https://doi.org/10.1016/j.jseaes.2017.07.036

Zhang, Z. J., and Klemperer, S. L. (2005). West-east variation in crustal thickness in northern Lhasa block, central Tibet, from deep seismic sounding data. J. Geophys. Res., 110(B9), B09403. https://doi.org/10.1029/2004JB003139

Zhao, J. M., Tang, W., Li, Y. S., Yao, C. L., Zhang, J., Wang, W., and Huang, Y. (2006). Lithospheric density and geomagnetic intensity in northeastern margin of the Tibetan plateau and tectonic implications. Earth Sci. Front. (in Chinese), 13(5), 391-400. https://doi.org/10.3321/j.issn:10052321.2006.05.014

Zhao, J. M. (2012). Geodynamic Conditions for Northern Margin of Tibetan Plateau (in Chinese). Beijing: Science Press. ISBN: 978-7-03-035472-3

Zhao, W. J., Wu, Z. H., Shi, D. N., Xiong, J. Y., Xue, G. Q., Su, H. P., Hu, D. G., and Ye, P. S. (2008). Comprehensive deep profiling of Tibetan Plateau in the INDEPTH Project. Acta Geosci. Sin. (in Chinese), 29(3), 328-342. https://doi.org/10.3321/j.issn:1006-3021.2008.03.007

Zou, C. Q., He, R. Z., Gao, R., Zhang, Z., and Zheng, H. W. (2012). Deep structure of the central uplift belt in the Qiangtang terrane Tibetan Plateaufrom teleseismic P-wave tomography. Chin. Sci. Bull. (in Chinese), 57(28-29), 2729-2739. https://doi.org/10.1360/972011-2430 